\title{
Using Circulation Systems for Special Collections: Tracking Usage, Promoting the Collection, and Addressing the Backlogs
}

\section{Beth M. Whittaker}

\begin{abstract}
Innovation and change are perennially hot topics in libraries: traditional library services are being rethought in response to emerging needs. At The Ohio State University (OSU) Libraries, a cross-departmental team responded to a new emphasis on assessment and outreach by using the circulation module of our integrated library system (ILS) to measure the use of special collections and archives materials. This endeavor enabled us to streamline workflow and document our successes, increasing knowledge across the libraries about circulation functions and practices. This project's findings may apply at other institutions to assist librarians in planning and implementing such a project.
\end{abstract}

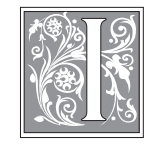

$\mathrm{t}$ is worth underscoring a few facts about special collections management. These valuable, rare, or unique materials usually are consulted by patrons in a secure reading room. Any desired copying or photography is handled by staff, to maintain the integrity of the materials and to ensure proper preservation measures and compliance with copyright or use restrictions. Despite perceived barriers to their use, education and outreach have become a greater focus for special collections in recent years, in keeping with the educational mission of larger parent institutions. ${ }^{1}$ The cultural heritage community has been increasingly concerned about the undocumented backlogs that plague many special collections, and bodies such as the Association of Research Libraries' Special Collections Task Force have consistently attempted to address this issue, particularly through the "Exposing Hidden Collections" initiatives. ${ }^{2}$ New resources are being directed to special collections to connect readers with currently inaccessible materials.

Traditionally, special collections operate parallel systems for many common library tasks. Registration of patrons is often very thorough, providing an additional security screening and documenting users' research interest in the specific material consulted. Retrieval of materials is also handled differently, echoing pre-automation practices with paper call slips. In many institutions,

Beth M. Whittaker is Head, Special Collections Cataloging, at The Ohio State University Libraries; e-mail: whittaker.50@osu.edu. The author wishes to thank Nancy Helmick, Library Catalog System Manager at the Ohio State University Libraries, and Nena Couch, curator of the Jerome Lawrence and Robert E. Lee Theatre Research Institute for the vision and cooperation that made this project possible. 
these call slips are then used to mark shelf location until the item is returned to its home. Although these paper records of circulation could be analyzed for data, time is short and this is rarely possible in the real world.

Special collections materials generally do not circulate outside a carefully controlled environment. Thus, many of the typical library circulation practices are often seen as superfluous in managing special collections and archives. Specific handling needs of these collections, such as frequent use by users not affiliated with the holding institution, and the need to retain records of users in the event of theft, often justify the belief that integrated library systems are insufficient to handle records of the collections' use. Since rare books, archives, and other materials are often held by collections that are part of a larger library system, this means in practice that an institution often has two systems: a sophisticated and expensive ILS for general collections and an idiosyncratic, yet effective, local system for special collections.

However, the increasingly sophisticated needs of the "general collection" including the need to manage electronic resources and the growth of collections in non-Roman languages - have driven ILS vendors to develop more flexible functionality. Special collections libraries can take advantage of this growth to eliminate redundant record keeping and reduce errors. Positive results include greater staff efficiency, increased availability of user statistics, and an overall greater understanding of collection use patterns.

This article focuses on the implementation of the circulation module of our ILS for special collections at The Ohio State University to assist librarians in defining the appropriate scope of such an implementation at their own institution. Details will vary by institution, of course, but by breaking out of the existing mindset that special collections "do not circulate," creative professionals will see opportunities to make similar changes.
Throughout this article, the word "circulation" refers to using the ILS to electronically track usage of materials within a secure reading room, a definition of circulation specific to the special collections environment. Although additional circulation of special collections materials is possible, perhaps even desirable, such as through interlibrary loan to other secure environments or for inclusion at exhibits, such decisions are independent of this project. ${ }^{3}$

\section{Literature Review}

The topic of circulating special collections materials is not very often addressed in the literature, which is to be expected given the peculiar nature of most collections' procedures. Articles on circulation analysis focus mostly on using circulation data to make decisions about collection development, such as purchasing additional copies of very popular items. Circulation data for special collections materials may also lead to collection development decisions, such as acquiring resources in an area previously thought less important to users. This, however, is not the primary motivation for implementing such a system.

Recent special collections literature has focused on a few issues brought to light by the current project, specifically the security of materials and records, and the need to increase outreach beyond the traditional users of special collections materials (i.e.,"scholars"). However, the author was unable to locate any study of how implementing a circulation system could assist with these goals, suggesting the prevalence of a two-system mindset.

\section{Possible Obstacles}

There are several possible objections to this type of project that could be advanced by both special collections professionals and colleagues from other parts of the library system.

\section{Maintenance of Circulation Records}

The first obstacle, and perhaps that with the most merit, is the need for security of 
records. In the event of theft or vandalism, special collections and archives rely on perpetual records of who consulted which materials, to track down wrongdoers. The primary professional organization for special collections professionals in the United States, ACRL's Rare Books and Manuscripts Section, recommends that registration information (including name, address, institutional affiliation (if any) and photo identification) be collected for each researcher who uses special collections materials and that these records be kept permanently. ${ }^{4}$ Of course, this conflicts directly with a larger library ethos that values privacy and confidentiality, advocating purging records so that they cannot be misused. For example, the American Library Association's Questions and Answers on Privacy and Confidentiality states:

In protecting the privacy rights and the confidentiality rights of library users, librarians should limit the degree to which personally identifiable information is monitored, collected, disclosed, and distributed. ${ }^{5}$

As one special collections administrator has stated about this apparent conflict, "Most integrated library systems are not designed to facilitate the separate management of special collections circulation records, if indeed they are designed to manage special collections materials at all." 6

The much smaller market share of special collections means that most ILSs are not designed to manage special collections in the way they accommodate resource sharing among large library systems or patron-initiated checkout, but the OSU experience proves that they can be adapted to do so. If objections are raised about the need to maintain a paper trail, an institution could always maintain separate files, using the traditional multipart call slip or a database, and use circulation data in the aggregate for statistical purposes. This approach seems to be quite common. ${ }^{7}$

\section{Need to Mark Collections}

To facilitate inventory control and rapid checkout, books, manuscripts, and other materials should be marked with barcodes or other tags that can be easily recognized by the system. Even if the larger "parent" collection of a library has undergone a large marking project, special collections might have been excluded. Professionals are still discussing the parameters for marking rare books. Many options exist to attach identifiers, ranging from those that are not permanent (such as paper flags or polyester filmstrips with the information) to those of a more high-tech nature, such as RFID (radiofrequency identification) tags affixed to materials. ${ }^{8}$ Marking a large collection can be very time-consuming, particularly if done in one batch. At OSU, the majority of the books and serial volumes in the special collections were labeled with call numbers and barcodes on acid-free flags many years ago, and the remainder are being labeled during preparation for a collections move or on an ad-hoc basis as they circulate. This approach certainly makes the task more manageable, and the result is more accurate volume counts and other information in the system. We highly recommend such an approach to inventorying, regardless of whether a circulation system will be used.

\section{Lack of Flexibility of ILSs}

Special collections librarians may have an unrealistically negative view of the flexibility of their organization's ILS, particularly if they do not have hands-on experience with its setup or management. Special collections staff may not have contributed to initial decisions about ILS implementation, with predictable results. Nonetheless, many setup decisions (such as creation of distinct "locations" or circulation loan rules) can be revisited to adapt the system to a more holistic environment.

Many systems are very flexible, allowing specific rules for special cases; the need to accommodate various types of material into catalogs, such as born digital 
resources, reserves, and foreign language materials, has driven the development of systems to become more accommodating to the needs of special collections as well. ${ }^{9}$ We found at OSU that other nonstandard materials, such as reserves or electronic materials, often presented "unique" needs that could be accommodated reasonably within the existing parameters of the circulation module. By fostering cooperation among those responsible for various types of materials, the needs of special collections can be met more easily.

\section{Perception of Effort}

To the objection that such a project would take too much work, we can only say that such an implementation does take time and effort. However, years of effort have gone into keeping paper statistics. It may appear easier to maintain the status quo than to revisit everyday procedures central to the collection's operation; but no system, no matter how long-lived, operates without a considerable amount of support.

Despite perceptions that using an automated circulation system would not work in a special collections and archives environment, a team of staff working on the project at OSU (including a systems manager, the head of special collections cataloging, and the curators responsible for each collection) have developed a system that not only overcomes these objections but returns significant results.

\section{Institutional Context}

To illustrate the scope of this implementation, it is important to understand that the OSU system has holdings of over four million bibliographic records and over seven million item records and is part of a statewide consortium of more than 85 institutions using a shared catalog containing 45.3 million records. Special collections at OSU consist of ten individual collections, each with distinct subject foci, located in several physical spaces. Although an ongoing renovation project will consolidate four collections into a shared space, each collection retains an identity and exists as a separate location in our ILS, Innovative Interfaces Inc.'s Millennium. Existing policy ensured that all recently acquired books and serials are reflected in the catalog, so new materials are added with bibliographic and item records, although many materials (particularly unpublished items) remain uncataloged.

Although staff have attempted over the years to standardize some administrative record keeping, even going so far as to create a common patron registration form, many differences in servicing materials persisted across the collections. Paper forms were used for both patron registration and material requests. Locations had different policies about who needed to register and how to handle materials "on hold" for users who would return later. Most important, all these paper forms were rarely, if ever, analyzed, due to the overwhelming nature of the task that was, understandably, a low priority. However, given the increased emphasis on outreach and serving broader user populations, curators were often asked to document use without having such information easily at hand. For example, the university's Academic Plan contains Strategies that include "Create a Diverse University Community" and "Help Build Ohio's Future," both of which suggest a need to reach beyond the traditional users of special collections. ${ }^{10}$

The team realized it would be essential to the project's success to start on a small scale, ensuring that any work done would be scalable to the much larger special collections environment. With both cataloged and uncataloged materials in the picture, and the need to accommodate both local (OSU) and visiting users, we decided to implement the project in phases.

\section{Implementation}

Phase One consisted of "circulating" cataloged materials at the Jerome Lawrence and Robert E. Lee Theatre Research Institute (TRI) to users affiliated with the university. These users already have patron 
records in the system. Fully cataloged materials (those with both bibliographic and item records) only needed small changes to their status, accomplished through batch updates, along with changes to the circulation parameters, to allow "checkout." Student assistants were then trained to use the circulation system instead of paper forms for these materials, with special documentation created to explain only those circulation functions for which there was a need.

After approximately one year of testing, with very encouraging results, we began Phase Two. This consisted of creating "on-the-fly" records for uncataloged material. Again, the ILS already had this functionality, but we made minor adjustments for special collections records. We also created a "cataloging queue" location, so that once materials were returned, they were funneled for priority cataloging. At the same time, senior staff members were authorized to create new patron records for nonaffiliated users. Both the on-the-fly bibliographic and item records and the patron records were created with templates devised by the project team, reducing the chance for data entry errors.

Several ILS system details required manipulation, of course. Materials needed to circulate without staff manually overriding their status each time, but local and consortial patrons, accustomed to having materials delivered, needed to be prevented from placing requests on these items. Luckily, such an item status already existed for in-library-use music materials.

Patron types are locally defined at OSU with a high degree of granularity; we can identify faculty, graduate students, etc. A new patron type for "special collections restricted" was created to track nonaffiliated users. We are exploring ways to define this category further that includes community members and visiting schol-

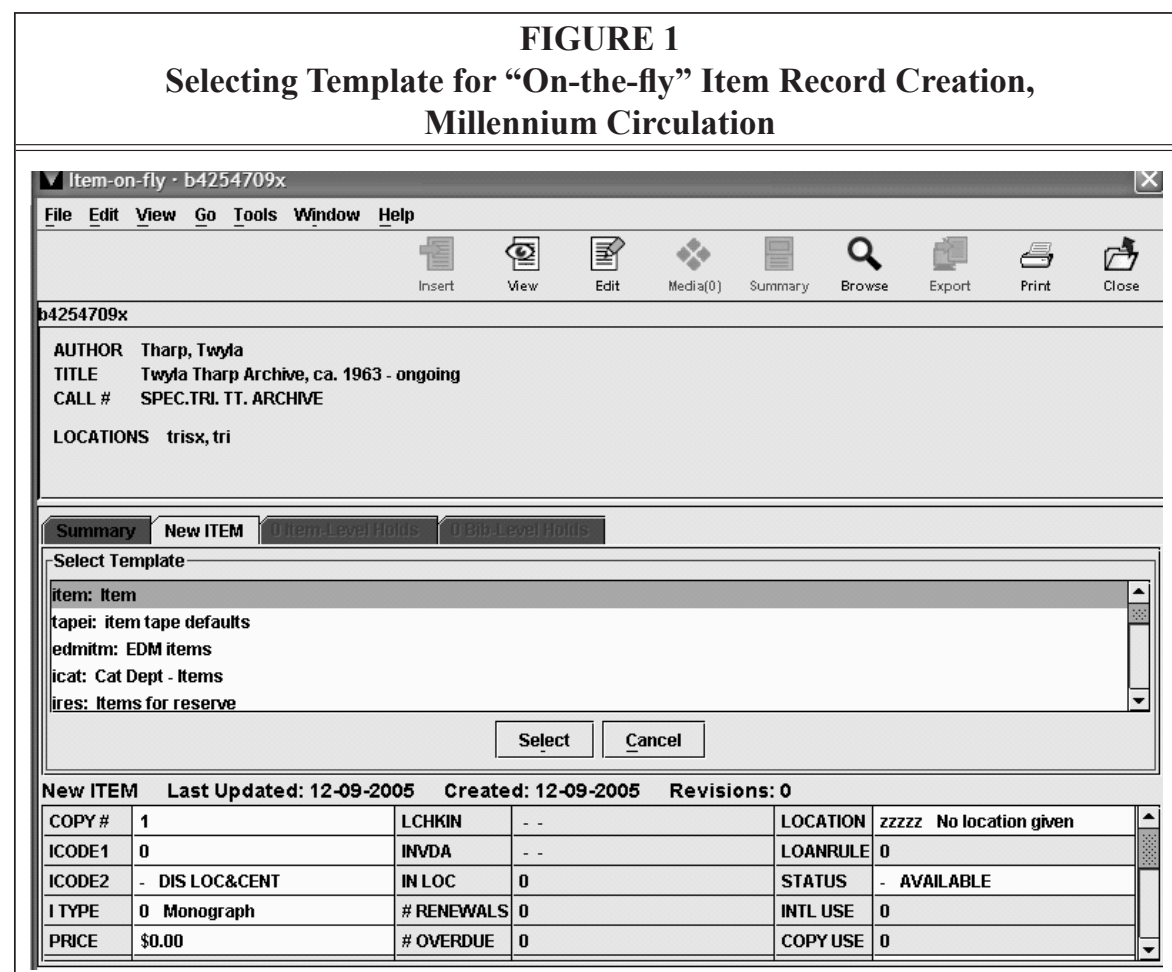

(C) Innovative Interfaces, Inc. 
ars. We are also implementing a special patron record to track interlibrary loan usage via photocopies.

Obviously, training was, and continues to be, an issue. We found that student assistants, previously assigned to the desk based more on their schedule than their experience, needed specific training and authorization for these tasks. Front -desk duties were assigned to fewer students than was previously the case. Learning the circulation interface took time for senior staff who had been more accustomed to the catalog's public interface. Ongoing training will be required as new staff arrive and as the inevitable changes are made to the ILS.

\section{Results}

Within the first few months of Phase One, the results were impressive. Circulation data showed a very high level of collection use by undergraduates and honors undergraduates, which was a pleasant surprise. This trend underscored the OSU curators' assertions that special collections support the curriculum and the mission of the university, in addition to being used by external researchers. As the months progressed, other trends were visible, and will be useful for planning purposes, particularly as the collections consolidate many operations in the renovated space.

Cataloging of nonbook materials has increased due to their circulation and subsequent placement in the cataloging queue. Manuscript collections, in particular, are being cataloged as they are used, with item records being created that more accurately reflect the extent of the collection. Additionally, the process for creating "on-the-fly" records led to adoption of a simplified process for cataloging free electronic books, created by collection managers themselves and using the same type of simplified documentation we used in our project.

The "promotional" aspect of this project should not be overlooked. Many materials that were not reflected in either OCLC or our local or consortial catalogs are now cataloged in these systems. As bibliographic records are repurposed and exposed through efforts like Open WorldCat, special collections materials at OSU will receive additional exposure.

\section{Future Plans}

The success of this limited implementation has encouraged the team to expand the project, with plans calling for all collections to be involved within a few years. The addition of another collection has revealed the need to address new issues, such as recalling material from remote storage and tracking use of subject clipping files, all of which can easily be accommodated through our system and which will continue to figure largely in special collections and archives administration.

Obviously, ongoing review of records and statistics will be needed to catch the

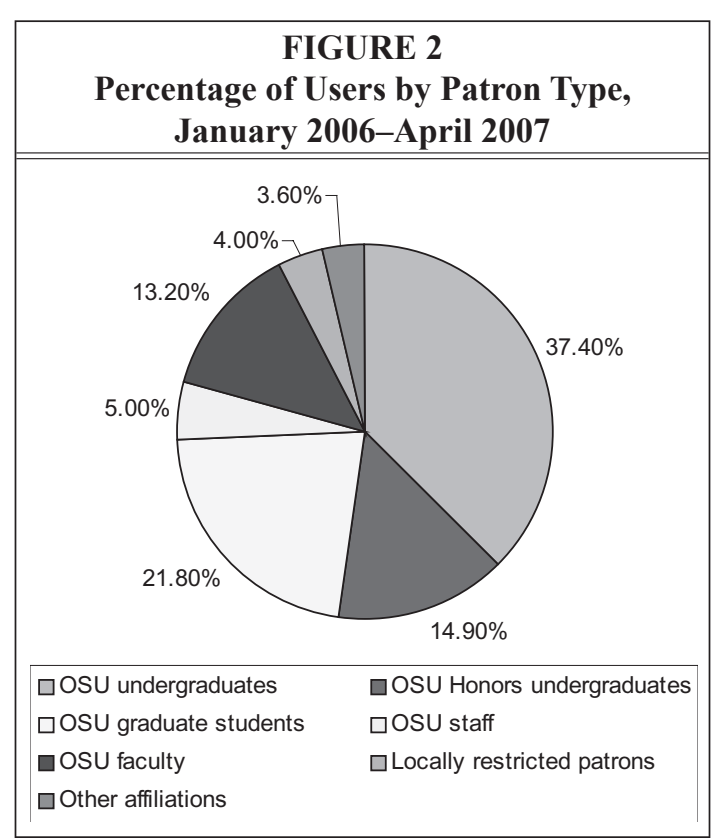




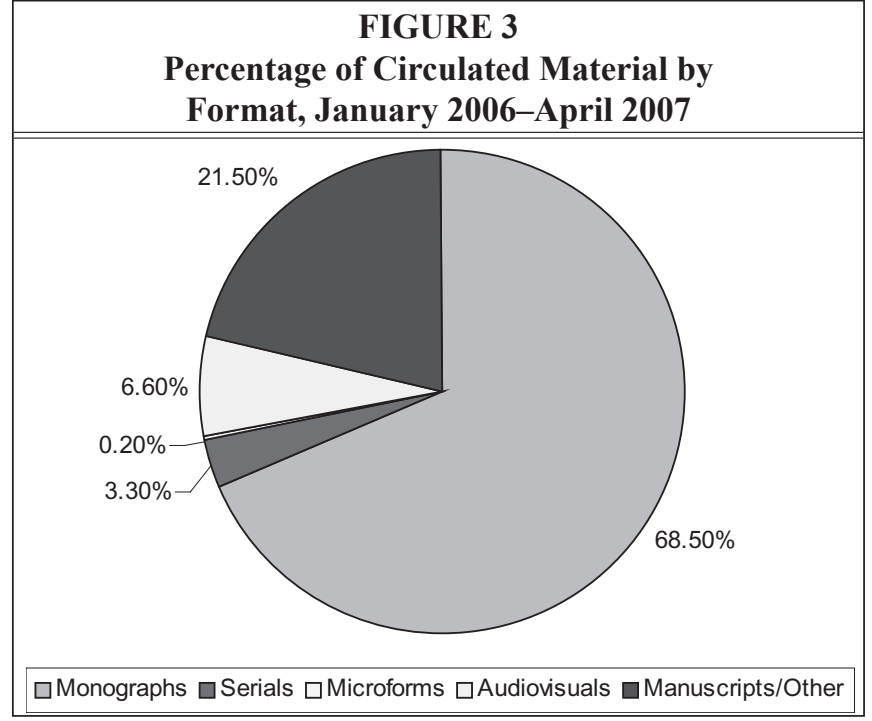

inevitable mistakes that creep in due to human error, but this is much easier to do than in the previous paper system. Standardization of registration and circulation practices will allow for a more accurate reporting of usage statistics as well as collection size.

\section{Recommendations for Other Institutions}

Based on our experiences, we would like to share some recommendations for those interested in exploring the use of their ILS's circulation system for special collections and archives.

Tailor the implementation to the needs of your organization. There might be simpler ways to accomplish your goals than we needed at OSU. Determine what kinds of information should be collected, and figure out how to get it, rather than creating more complications than necessary. For example, we explored the option of using the "track in-house use" function for this project, a feature that is designed to count use of serials found scattered throughout the stacks but not actually checked out. This practice might be sufficient for some collections.

Cooperation and collaboration are essential. In addition to the expertise of ticular institution.

systems staff, consult with circulation experts even if it means educating them about special collections. We were surprised to learn that many things we thought would be exceptional were already possible in limited ways with our circulation module. In addition, system vendors may provide a broader view of the possibilities of the software than those "in the trenches" of a par-

Flexibility is a must, both in the management of the collection and the implementation of the system. Since student assistants or staff will be critical to the success of this kind of project, it is crucial to provide them with support and to listen to their feedback. Using the current generation of systems is much easier than those of years past.

Small steps are often very effective. If resistance is encountered based on one or two perceived limitations, it might be possible to address these perceptions without abandoning the entire project. Finally, continue to use whatever system is currently in place for as long as is necessary. Eventually, the superiority of the automated system will become obvious.

\section{Conclusion}

While using an integrated library system is hardly revolutionary in the age of social networks, user tagging, and other cuttingedge library applications, the rethinking of processes involved in this project has in many ways transformed "circulation" of special collections and archives. The emphasis on outreach and assessment that drives a culture of accountability has reached libraries, and, in respond- 


\section{Using Circulation Systems for Special Collections 35}

ing to this need, OSU has realized many benefits.

In addition to simplifying the daily work of materials management, this project continues to provide a great deal of useful information about the users of our materials that will be essential in the future for projects such as seeking grants and making internal funding requests. At the same time, the involvement of library staff across the organization has led to a type of cross-training that has given all of us a higher level of appreciation for the different aspects of library service in which we specialize. Most important, we are "doing right" by the library materials and patrons we serve every day by making our collections more accessible to the world.

\section{Notes}

1. Daniel Traister, "Is There a Future for Special Collections? And Should There Be? A Polemical Essay," RBM 1, no. 1 (2000): 54-76.

2. Association of Research Libraries Exposing Hidden Collections initiatives. Available online at www.arl.org/rtl/speccoll/hidden/l. [Accessed 24 February 2007].

3. Association of College and Research Libraries, Guidelines for the Interlibrary Loan of Rare and Unique Materials, available online at www.ala.org/ala/acrl/acrlstandards/rareguidelines.htm and Guidelines for Borrowing and Lending Special Collections Materials for Exhibition, available online at www.ala.org/ala/acrl/acrlstandards/borrowguide.htm. [Accessed 23 February 2007].

4. Association of College and Research Libraries, Guidelines for the Security of Rare Books, Manuscripts, and Other Special Collections, section VI. Researchers. Available online at www.ala. org/ala/acrl/acrlstandards/securityrarebooks.htm. [Accessed 30 November 2007].

5. American Library Association. Available online at www.ala.org/Template.cfm?Section=inte rpretations\&Template=/ContentManagement/ContentDisplay.cfm\&ContentID=141474. [Accessed 24 February 2007].

6. Christian Dupont, "Online/automated circulation / patron record retention." Available online to list subscribers at http://lists.ala.org/wws/arc/rbsm/2006-08/msg0000.html. [Accessed 6 August 2006].

7. Christian Dupont, "Online/automated circulation / patron record retention-summary of responses to date." Available online to list subscribers at http://lists.ala.org/wws/arc/rbsm/200608/msg00004.html. [Accessed 14 August 2006].

8. E. C. Schroeder, "RFID in Special Collection Libraries." Available online to list subscribers at http://lists.ala.org/wws/arc/rbsm/2006-10/msg0000.html. [Accessed 2 October 2006].

9. Beth M. Russell, "Description and Access in Rare Books Cataloging: A Historical Survey," Cataloging \& Classification Quarterly 35 no. 3/4 2003: 518

10. The Ohio State University Academic Plan. Available online at www.osu.edu/academicplan/strat.php. [Accessed 24 February 2007]. 